Rhode Island College

Digital Commons @ RIC

$5-1-2013$

\title{
Prevention Management of Postoperative Nausea and Vomiting in Ambulatory Setting: How Well are We Identifying Patients with Motion Sickness?
}

Sheila A. Capasso

Rhode Island College

Follow this and additional works at: https://digitalcommons.ric.edu/etd

Part of the Nursing Commons

\section{Recommended Citation}

Capasso, Sheila A., "Prevention Management of Postoperative Nausea and Vomiting in Ambulatory Setting: How Well are We Identifying Patients with Motion Sickness?" (2013). Master's Theses, Dissertations, Graduate Research and Major Papers Overview. 217.

https://digitalcommons.ric.edu/etd/217

This Major Paper is brought to you for free and open access by the Master's Theses, Dissertations, Graduate Research and Major Papers at Digital Commons @ RIC. It has been accepted for inclusion in Master's Theses, Dissertations, Graduate Research and Major Papers Overview by an authorized administrator of Digital Commons @ RIC. For more information, please contact digitalcommons@ric.edu. 


\title{
PREVENTION AND MANAGEMENT OF POSTOPERATIVE NAUSEA AND VOMITING IN AMBULATORY SETTING: HOW WELL ARE WE IDENTIFYING PATIENTS WITH MOTION SICKNESS?
}

\author{
By
}

Sheila A. Capasso RN, BSN, CAPA

A Major Paper Submitted in Partial Fulfillment

Of the Requirements for the Degree of

Master of Science in Nursing

in

The School of Nursing

Rhode Island College

2013 


\begin{abstract}
Postoperative nausea and vomiting (PONV) and postdischarge nausea and vomiting (PDNV) continue to be a serious problem in the ambulatory setting. These symptoms are among the most undesired complications following surgery and can adversely affect the quality of recovery for many patients. Previous research has concluded that the identification of risk factors for PONV/PDNV is a first step in developing effective prevention strategies. The purpose of this study was to examine the incidence of PONV/ PDNV in the ambulatory setting in female clients who were treated with transdermal scopolamine (TDS) for motion sickness as compared to those patients who were not treated with TDS. The study design was a two-group retrospective chart review. Of the group identified with a positive history and not treated with TDS, 54\% $(n=6)$ developed PONV /PDNV as compared to $26 \%(n=3)$ that were treated. This pilot study provided preliminary support that preoperative identification of PONV/PDNV risk factors and treatment with TDS reduces PONV/PDNV. Standardized, comprehensive risk factor identification in the preoperative period is indicated.
\end{abstract}




\section{Acknowledgements}

I would like to express my special thanks to Cynthia Padula, $\mathrm{PhD}$ this project required a lot of guidance and assistance and I am truly thankful to have had your support from the initial idea to the completion of this project. I would also like to thank the many professors that contributed to my education.

To Susan DiBlasi, MSN who gave me wonderful advice I have been blessed to know you as a colleague instructor, and friend.

I am indebted to my student colleagues for providing support throughout the program, and especially to my friend Susan Amalfitano, BSN whose support encouraged me to continue in my education through some very difficult days.

Finally, I like to thank my family especially my husband Donald and children for your support and encouragement. 
This paper is being submitted to Journal of PeriAnesthesia Nursing for publication consideration. 


\section{Table of Contents}

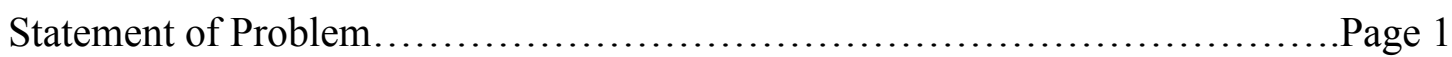

Literature Review............................................. Page 2

Conceptual Model..................................................Page 9

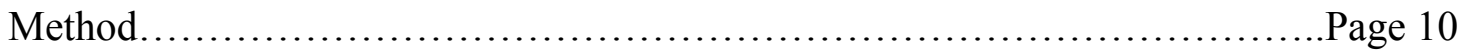

Results...................................................... Page 12

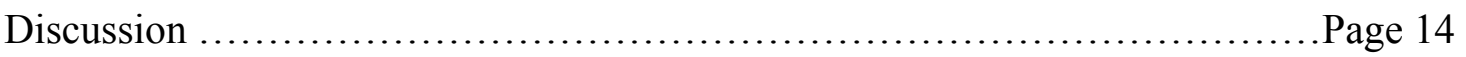

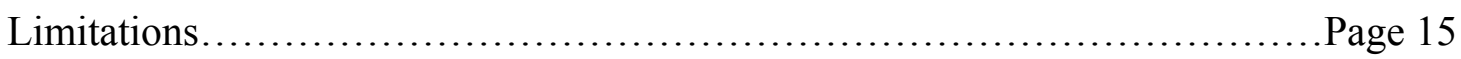

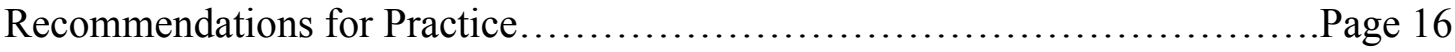

Conclusion...................................................... 16

References....................................................... 18

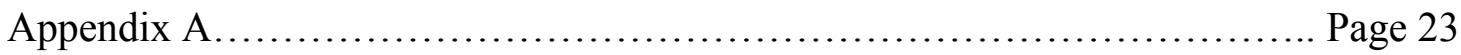


Prevention and Management of Postoperative Nausea and Vomiting in Ambulatory Surgery: How Well Are We Identifying Patients with Motion Sickness?

\section{Background / Statement of Problem}

Postoperative nausea and vomiting (PONV) is a serious problem in the ambulatory surgical setting. Identified as a surgical problem since 1848, after the introduction of anesthesia, PONV is one of the most undesired complications following surgery. ${ }^{1}$ One third of all patients requiring anesthesia for surgery will develop PONV, and as many as $30 \%$ to $50 \%$ of outpatients will develop postdischarge nausea and vomiting (PDNV) after their arrival home. ${ }^{2}$ From 1996 to 2006, the number of outpatient surgery visits in the United States (US) increased from 20.8 to 34.7 million, accounting for half of all surgeries ${ }^{3}$ With the increasing number of outpatients surgeries, PDNV will also increase, making the identification of risk factors and preventing PONV and PDNV an important factor in the saftey and satisfaction of these patients.

PONV encompasses three main symptoms, nausea, vomiting and retching, which may occur separately or in combination after surgery. ${ }^{4}$ Each vomiting episode delays discharge from recovery room by 25 minutes. $^{5}$ It is estimated that approximately $0.2 \%$ of all surgical patients may experience intractable PONV, leading to delays in discharge from recovery areas and unanticipated hospital admissions following ambulatory surgery. ${ }^{6}$ 
A history of motion sickness or prior PONV are considered independent predictors for PONV, likely because the patient has already established a reflex arc for vomiting. ${ }^{7}$ Motion sickness is a syndrome that occurs in response to a real or perceived motion. ${ }^{8}$ Early assessment and treatment of patients at risk for PONV before surgery, including those with a history of motion sickness, can minimize negative outcomes. The purpose of this study was to examine the incidence of PONV/ PDNV in the ambulatory setting in female clients treated with transdermal scopolamine for motion sickness as compared to those patients who are not treated with scopolamine.

\section{Literature Review}

The processes of nausea, vomiting, and retching are coordinated by the vomiting center in the brain. ${ }^{9}$ Nausea is a subjective and unpleasent sensation that is associated with the urge to vomit. Vomiting and retching are objective patient experiences; vomiting (emesis) includes the forceful expulsion of gastric contents from the mouth, and retching represents an unproductive effort to vomit. ${ }^{10}$ Stimulation of these processes can be initated from the periphery and centrally from the CNS. Stimuli are relayed from the periphery to the vomiting centre by the autonomic nervous system afferent neurons of the vagus nerve. There is afferent input to the area postrema from the vagal and glossopharyngeal nerves. Central cerebral sensory stimuli occur directly and are transmitted by the chemoreceptor trigger zone (CTZ) area postrema, and nucleus of the solitary tract in the lateral reticular formation of the medulla to the vomiting centre.

Chemicals in the CSF and blood have a direct stimulating effect at the vomiting centre. ${ }^{9}$ 
The areas in the CNS associated with balance, vasomotor activity, salivation, respiration and bulbar control are located near, and have innervations to, the vomiting centre. The close proximity of these areas to the vomiting centre corresponds to the physiological reactions seen in PONV, such as tachypnea, tachycardia, sweating, increased swallowing, cardiac dysrhythmias, and motion sickness. ${ }^{9}$

Postoperative nausea and vomiting occur after $25 \%$ to $30 \%$ of surgeries and significantly contribute to patients' discomfort, distress, and dissatisfaction . ${ }^{9}$ Among high-risk patients, the incidence of PONV can be as high as $70 \%{ }^{11}$ The most common of postsurgical complications, PONV and PDNV affect approximately 25 million patients worldwide yearly with an estimated financial impact of several million dollars. ${ }^{12,13}$ The incidence of PDNV is more difficult to document due to lack of reporting, but it has been estimated that one-third of patients will experience PDNV after discharge from ambulatory setting. ${ }^{2}$ With more than $60 \%$ to $65 \%$ of surgeries performed in an ambulatory setting, PDNV is a significant problem affecting thousands of patients . ${ }^{2}$ Until recently, there has been no clear definition of PDNV, although the term is related to discharge of a patient after ambulatory surgery. A strategic work team, convened by American Society of PeriAnesthesia Nurses (ASPAN), distinguished PDNV from PONV. PDNV was defined as nausea or vomiting that occurs after discharge from a surgical facility, while PONV was identified as occurring within the first 24 hours of surgery. ${ }^{14}$ The question as to whether the person who is nauseated or has emesis during transport home is diagnosed with PONV or PDNV remains. ${ }^{15}$ 
Despite the use of prophylactic antiemetics for preventing PONV, many surgical patients undergoing general anesthesia still experience PONV in the post anesthesia care unit, the hospital, and at home after discharge. ${ }^{16}$ ASPAN developed practice guidelines designed to assist the practitioner to identify high-risk patients and develop a multimodal plan of treatment; risk factors were identified as surgery related, anesthesia related, and patient related. ${ }^{14}$ Surgery related factors that increase risk include type of surgery, length of surgery, and anesthesia techniques used. Surgeries that have a direct relationship on increased incidence of PONV include eye, oral, plastic, ear, nose and throst, head and neck, gynecological, obstetric, laproscopic and abdominal procedures. ${ }^{17}$ Longer operations (greater than three hours) allow for longer exposure to lipid soluble, potentially emetic intravenous, and inhalation gas anesthetics, all of which can cause an increase in PONV. ${ }^{18}$

Compared with a purely regional anesthetic technigue, general anesthesia is associated with a significantly higher incidence of nausea, vomiting, and overall PONV. ${ }^{19}$ This fact raises the question as to the contribution of the drugs used during surgery. There have been several meta-analysis that have shown decreased nausea and vomiting when propofol is used as opposed to inhalation agents. ${ }^{20,21,22}$ Some anesthetic agents increase the risk of PONV. Apfel and colleagues conducted a large clinical trial of 5199 patients. Each patient had at least a $40 \%$ risk of PONV according to a simplfied risk score, based on the presence of at least two risk factors. This trial simultaneously evaluated 
antiemetic efficacy and anesthetic interventions. All the tested antiemetics appeared similarily effective; substituting propofol for a volatile anesthetic reduced the rate of PONV by $19 \%$, whereas substituting nitrogen for nitrous oxide reduced the risk by $12 \%$. Combining these two anesthetic strategies ( total intravenous anesthesia) reduced the risk by as much as any single antiemetic. In a trial comparing nitrous oxide group with an oxgen enriched air group, Myles et al. ${ }^{23}$ found that the group receiving nitrious oxide had significantly more severe adverse events, including pulmonary complications, wound infections, and fever; the oxgen enriched air group had lower rates of severe nausea and vomiting.

Patient specific risk factors for PONV/ PDNV include female gender, non-smoking status, and the use of opioids for postoperative analgesia, motion sickness, or previous PONV. ${ }^{10,16,24}$ Nonsmokers are at higher risk of development of PONV than smokers. ${ }^{7}$ Chatterjee et al. ${ }^{6}$ identified that chronic exposure to smoke, in particular polycyclic aronmatic hydrocarbons, produced changes in liver microsomal enzymes that may change the metabolism of drugs used in the peri-operative period and the capicity of these drugs to produce PONV. ${ }^{6}$ There is a three fold increase in the incidence of PONV in patients who have a history of PONV or motion sickness. ${ }^{4}$ A history of motion sickness or prior PONV/PDNV are considered independent predictors of PONV. ${ }^{7}$

Motion sickness is a syndrome that occurs in response to real or perceived motion, and includes gastrointestinal, central nervous system, and autonomic symptoms. ${ }^{8}$ Motion 
sickness occurs following stimulation of the vestibular apparatus of the inner ear; following this stimulation, transmission of impulse to the CTZ and vomiting centre occurs, relaying to the CNS the sensation of nausea and motion sickness. Vomiting may then occur. Characteristics that show some correlation to motion sickness are sex, age, hormonal factors, disease that alter vestibular or visual sensory cues, and migraine ${ }^{8}$ Physical signs of motion sickness include sense of dizziness, nausea, belching, increased salavation, warmth, and diaphoresis, along with a feeling of malaise. ${ }^{8}$ In two independent investigations, Cheung et al. ${ }^{25}$ found no effect of menstrual cycle on motion sickness, whereas Golding et al. ${ }^{26}$ found an increased susceptibility to motion sickness. ${ }^{27}$ Accurate assessment of motion sickness and effective treatment are key.

Knowledge of risk factors is essential for the identification of high-risk patients and effective multimodal management of PONV. ${ }^{28}$ Several risk assessment tools have been developed using multiple regression analysis to identify factors that are strong independent predictors of PONV. ${ }^{28}$ Palazzo and Evans, ${ }^{29}$ Koivuranta et al., ${ }^{30}$ and Apfel et al. ${ }^{24}$ each developed risk assessment tools. Each tool included the same five variables in the risk score, including female gender, nonsmoking status, history of PONV, history of motion sickness, and postoperative use of opioids.$^{28}$ The Apfel model has been successfully used to predict which patients are likley to develop PONV. ${ }^{12}$ On the basis of the Apfel et al. ${ }^{12}$ risk scoring system, a female patient who has had a history of PONV and is receiving opioids for pain has a $60 \%$ chance of developing PONV. ${ }^{31}$ 
It is recommended that any risk model must undergo external validation before it can be used in clinical practice. ${ }^{10}$ Given the limitations in validating PONV risk factors, it is not surprising that scoring systems have shown only poor to moderate accuracy. Despite the limitations, their use to better tailor antimetic interventions has been shown to significantly reduce the incidence of PONV particularly in high risk patient populations. ${ }^{10}$ The prediction of PONV/PDNV relies on the assessment of the patient, and places emphasis on how well the evaluation is completed. In a review done by Eberhart \& Morin, risk score assessment was found to be a useful tool to predict PONV, though anaesthesiologists tend not too use them. ${ }^{32}$ Criticism of the general application of PONV scores is based not only on the systematic lack of external validation of the scores but also on other methodological issues. ${ }^{32}$

Clinical practice guidelines for managing PONV and PDNV have been developed by the American Society of Anesthesiologists (ASA), ${ }^{33}$ the American Society of Perianesthesia Nurses (ASPAN), ${ }^{14}$ and the Society of Ambulatory Anesthesia (SAMBA). ${ }^{13}$ ASA guidelines provide an evidence-based reference tool for anesthesia providers in the management of patients at risk for PONV/PDNV. ${ }^{33}$ The ASA guidelines include: risk factor identification for PONV using the simplified Apfel et al. ${ }^{24}$ risk factor assessment tool; recommendations to reduce the baseline risk for PONV and identify the optimal approach to PONV prevention and therapy; guidelines to determine the choice and timing of antiemetic administration; and identify the most effective monotherapy and combination therapy. ${ }^{33}$ 
Antiemetic medications are the most common treatment for PONV. Because there is no single receptor or stimulus for PONV, no one amtiemetic will be effective in all patients. ${ }^{31}$ In 2007, SAMBA revised ASA guidelines and made recommendations for treating PONV/PDNV to include transdermal scopolamine (TDS) as one of the first and second line antiemetic for use in motion sickness. ${ }^{12}$ In 2001, the US Food and Drug Administration approved the use of transdermal scopolamine (TDS) for the prevention of PONV. TDS is a long acting prophylactic antiemetic initially developed to prevent motion sickness; it is a centrally acting anticholinergic agent. ${ }^{34}$ Scopolamine is an effective preoperative antiemetic; it crosses the blood brain barrier and blocks cholinergic stimulation of the vomiting center from both the gastrointestinal tract and the vestibular center. TDS has been shown to be associated with significant reductions in PONV with both early and late patch application during the first 24 hours after the start of anesthesia. ${ }^{34}$ Anesthesia departments play a key role in promoting the adherence to guidelines by monitoring the incidence of PONV and instituting policies that align with current recommendations. ${ }^{35}$

ASPAN organized an Evidence Based Practice Strategic Work Team (SWT) consisting of 16 multi-disciplinary, multi-specialty experts to review published evidence related to the prevention and/or management of PONV/PDNV. The guidelines apply to both inpatient and outpatient settings and to procedures performed in the operating room, as well as in other locations where sedation and anesthesia may be given. ${ }^{14}$ 
Recommendations included prophylactic treatment of PONV based on the patients' level of risk, determined by risk factor assessment. Simplified risk factor tools establish the patients' baseline risk for PONV, and the number of interventions based on the level of risk. ${ }^{12}$ ASPAN included the simplified risk factors tools as developed by Apfel et al. ${ }^{24}$ and Koivuranta et al. ${ }^{30}$ to establish the patient's baseline risk for developing PONV. ${ }^{14}$ Prophylactic recommendations include anesthesia related (total intravenous anesthesia TIVA), pharmacologic therapeutic (hydration, and pain management), and complementary interventions (acupoint). ${ }^{14}$ In addition to pharmacologic agents recommened by ASA, PONV prophylaxis, $\mathrm{H} 1$ receptor blockers (antihistamines) and the scopolamine patch were recommend in the case of patients with motion sickness. ${ }^{14}$

\section{Conceptual Model}

The Symptom Management model was used to guide this research; the model was developed in 1994, by the University of California, San Francisco (UCSF) Symptom Management Team and revised in 2001 to include broad based symptom management. ${ }^{36}$ A symptom is a subjective experience, reflected in the bio-psychosocial functioning, sensations, or cognition of an individual, ${ }^{36}$ as compared to a sign, which is defined as any abnormality indicative of disease that is detectable by the individual or by others. ${ }^{36}$ The UCSF model includes signs when needed to assess disease status and to evaluate and verify the effectiveness of management strategies. ${ }^{36}$ The Symptom Management Model is based on the premise that effective management of any given symptom or group of 
symptoms demands that all three dimensions be considered: the interrelatedness of the symptom experience; symptom management strategies; and outcomes.

The revised model recognizes the domains of nursing science, person, health/illness and environment, which influence the three dimensions. The symptom experience includes an individual's perception of the symptom, evaluation of the meaning of the symptom, and response to a symptom. The goal of symptom management is to avert negative outcomes, and begins in the assessment phase of the symptom experience, followed by identifying and focusing on intervention strategies. Interventions are targeted at one or more components of the individual's symptom experience to achieve desired outcomes. ${ }^{36}$ Although the physiology of the vomiting center is understood; the pathways to control nausea and vomiting are not well defined. ${ }^{36}$

\section{Method}

The purpose of this study was to examine the incidence of PONV/PDNV in the ambulatory setting in female clients who were treated with TDS for motion sickness as compared to those who were not treated with TDS.

\section{Research Design}

The study was designed as a two-group retrospective chart review; the groups included a convenience sample of 156 female clients. Group 1 included those female clients who were identified as having a previous history of PONV/PDNV or motion sickness and were treated with TDS; Group 2 included females with a history of motion sickness who 
were not treated with TDS. The hypothesis was that patients identified with a previous history and/or motion sickness and treated with TDS preoperatively would have a decreased rate of PONV/PDNV, as opposed to those who were not treated with TDS.

Site

This study was conducted at The Fain Health Center, an ambulatory surgical unit at The Miriam Hospital, Providence R.I. The Fain Health Center provides care to clients undergoing ambulatory surgery.

\section{Sample}

Inclusion criteria included those female clients 17 years or older who had received general anesthesia for laproscopic, gynecological, or breast surgery and had been identified as having a history of PONV/PDNV or motion sickness, either through preoperative nursing assessment or through anesthesia assessment, and were either treated with TDS or not treated with TDS. Exclusion criteria included those who met inclusion critera but had received emetrogenic or antiemetic drugs within the 24 hours prior to surgery, as well as clients for whom TDS was contraindicated.

\section{Procedures}

Prior to data collection, permission was obtained from the Lifespan and Rhode Island College Institutional Review Boards (IRB). Institutional permission was also obtained from the Director of Surgical Services. After approval, the student investigator obtained a list of clients from the surgical schedule whose surgeries occurred between January and October 2012. The list was submitted to health information services via a medical record request form, and requested records were retrieved by the health information staff. Once 
retrieved, the student investigator reviewed records for the identified inclusion/ exclusion criteria.

The student investigator extracted relevant data, using a data collection tool developed from the literature review and clinical experience (Appendix A). The focus of the tool was on risk factors for PONV/PDNV as well as anti-emetics used and use of TDS. Documentation reviewed included the preadmission assessment form, anesthesia assessment form, and the pre-procedure verfication form.

\section{Data Analysis}

Descriptive statistic techniques were used to summarize findings. Differences between groups related to PONV/PDNV were examined.

\section{Results}

A total of 180 records were reviewed; 24 were not included because those clients had received modified anesthesia as compared to general anesthesia. Prophylactic antiemetics administered to all clients intraoperatively included dexamethasone $4 \mathrm{mg}$ (Decadron) and ondansetron 4mg (Zofran). Data from remaining records $(n=156)$ were then further examined to identify those in which a history of PONV/PDNV or motion sickness was identified, typically during the preadmission interview or when interviwed by the anesthesiologist the day of surgery. A total of 26 clients (17\%) were identified as having a history of PONV/PDNV or motion sickness. The characteristics of the 26 clients are illustrated in Table 1. 
Table 1

Risk Characteristics of Clients Identified with PONV/PDNV or Motion Sickness

\begin{tabular}{|c|c|c|c|}
\hline $\begin{array}{l}\text { Total Clients } \\
\text { Identified with } \\
\text { PONV/PDNV or } \\
\text { Motion Sickness } \\
(\mathrm{n}=26 ; 16.6 \%)\end{array}$ & & $\begin{array}{l}\text { Treated with } \\
\text { TDS } \\
\mathrm{n}=15(58 \%)\end{array}$ & $\begin{array}{l}\text { Not } \\
\text { Treated with } \\
\text { TDS } \\
\mathrm{n}=11(42 \%)\end{array}$ \\
\hline $\begin{array}{l}\text { Smoking Status } \\
\text { Never } \\
\text { Former } \\
\text { Current }\end{array}$ & $\begin{array}{l}n=22(85 \%) \\
n=3(11 \%) \\
n=1(5 \%)\end{array}$ & $\begin{array}{l}\mathrm{n}=15(100 \%) \\
\mathrm{n}=0 \\
\mathrm{n}=0\end{array}$ & $\begin{array}{l}\mathrm{n}=7(73 \%) \\
\mathrm{n}=3(18 \%) \\
\mathrm{n}=1(9 \%)\end{array}$ \\
\hline $\begin{array}{l}\text { Type of surgery } \\
\text { Laproscopic } \\
\text { Breast } \\
\text { Gynecological }\end{array}$ & $\begin{array}{l}n=12(46 \%) \\
n=13(50 \%) \\
n=1(4 \%)\end{array}$ & $\begin{array}{l}\mathrm{n}=6(40 \%) \\
\mathrm{n}=8(53 \%) \\
\mathrm{n}=1(7 \%)\end{array}$ & $\begin{array}{l}\mathrm{n}=6(55 \%) \\
\mathrm{n}=5(45 \%) \\
\mathrm{n}=0\end{array}$ \\
\hline
\end{tabular}

The age range of clients was from 17 to 75 with a mean of 44.2 years. The majority of the sample were non smokers $(n=22 ; 85 \%)$ and half had undergone breast procedures $(n=$ $13)$.

The remaining 130 medical records $(83 \%)$ included no documentation as to whether there was a history of PONV/PDNV or motion sickness. None of these forms have a specific area for documentation of risk factors, and only the preadmission form had a question asking if the client or family members had any difficulty with anesthesia. The client recruitment breakdown is illustrated in Figure 1. 


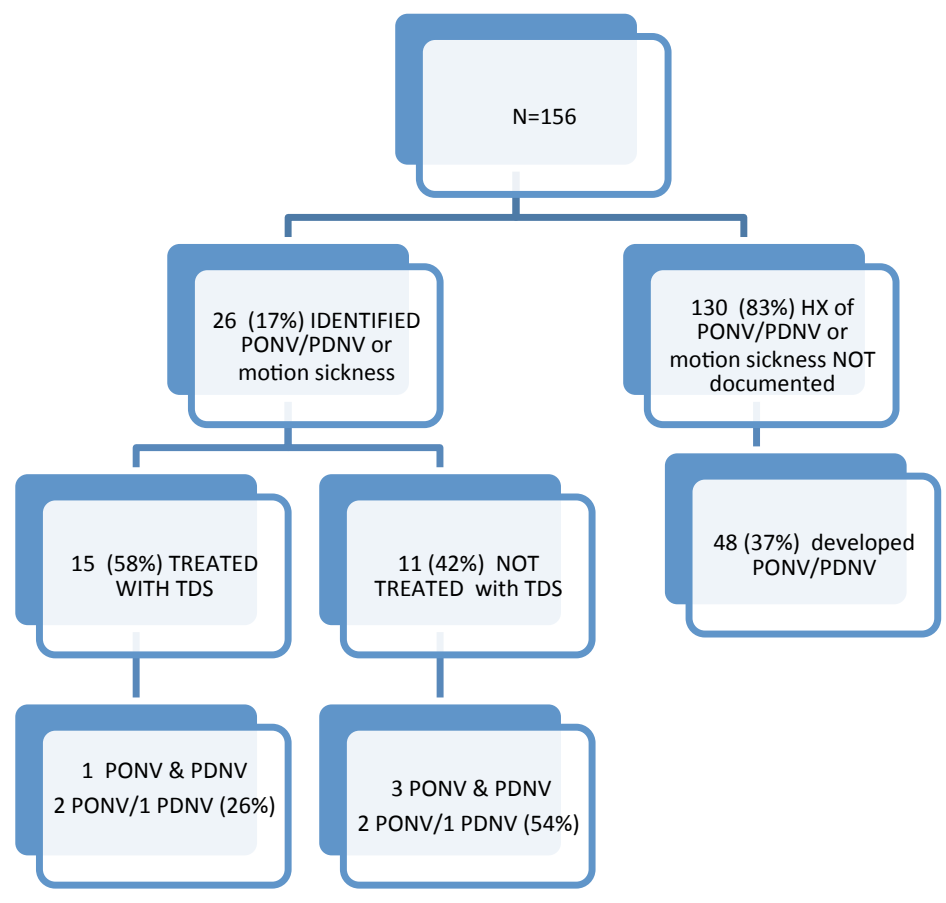

Figure 1. Distrubution of PONV/PDNV

Twenty six clients (17\%) identified having a history of PONV/PDNV or motion sickness. Of those $26,15(58 \%)$ were treated with TDS, while $11(42 \%)$ were not treated. Of those that were treated with TDS $(n=15), 26 \%(n=3)$ developed PONV/PDNV as compared to those with a history of PONV/ PDNV or motion sickness $(\mathrm{n}=11)$ and not treated $(\mathrm{n}=6 ; 54 \%)$. In the group without documentation related to whether a history of PONV/PDNV or motion sickness existed $(n=130), 48$ ( $37 \%$ ) developed PONV/PDNV.

\section{Discussion}

The purpose of this study was to examine the incidence of PONV/ PDNV in the ambulatory setting in female clients who were treated with TDS for motion sickness as 
compared to those clients who were not treated with TDS. PONV/PDNV continues to be a significant problem despite the use of antiemetics and negatively affect patients' quality of recovery and patient satisfaction. In this study, when a history of PONV/ PDNV or motion sickness was identified and treated with TDS, PONV/ PDNV were reduced as compared to when not treated with TDS (26\% versus 54\% respectively).

Guidelines have been developed by ASA, ${ }^{33}$ ASPAN, ${ }^{14}$ and SAMBA ${ }^{13}$ to assist clinicians with an evidence-based, practical approach to the prevention and/ or management of PONV and PDNV. These guidelines were developed to serve as a resource to anesthesia providers and perianesthesia nurses involved in the care of patients at risk for PONV/ PDNV. ${ }^{14}$ Although these guidelines serve as a tool for the management of PONV, they also suggest that not all patients will benefit from antiemetic prophylaxis, and that the identification of patients who are at increased risk leads to the most effective use of therapy. ${ }^{4}$ This study provided supportive evidence that preoperative identification of risk factors and treatment with TDS can potentially reduce PONV/PDNV.

\section{Limitations}

Given that this was a retrospective design, the information retrieved from records was limited to what was documented. Results of the study may have been affected by certain variables that were not controlled for including the use of volatile anesthetics, and postoperative use and administration of opioids. This study was limited by a small sample size and the limited amount of demographic data that was collected. 


\section{Recommendations for Practice}

Nausea and vomiting are commonly feared by surgical patients, and remain the source of significant anxiety for patients and families. PONV/PDNV also has the potential to negatively impact patient outcomes, and can result in increased length of stay for the patient and the institution. Prevention of PONV/PDNV is a high priority for nurses in the perianesthesia setting; when prevention is not possible, effective treatment is the primary goal. Reliable and valid risk assessment tools are available for use in clinical settings, and recommended for use by ASA and ASPAN. Consistent use of a risk assessment tool to identify risk factors for PONV/PDNV before surgery is recommended.

\section{Conclusions}

In spite of the advances made in anesthesia and in management of post-operative symptoms, PONV/ PDNV continue to be a problem for surgical patients. Kapur referred to PONV as the "big little problem". ${ }^{37}$ Identification of high-risk patients is essential to the prevention of PONV/PDNV. The Symptom Management Model guided this research and is based on the assumption that the symptom does not have to be experienced by an individual for the individual to be at risk for the development of the symptom. ${ }^{36}$ It is easier to treat nausea and prevent vomiting than to stop vomiting once it has started. ${ }^{1}$ Collaboration and communication of risk factors between the anesthesia team and nursing staff members must occur in order to bring best practices to the patient. Accurate identification of PONV/PDNV risk factors in the interdisciplinary treatment plan is an essential first step; perianesthesia nurses are positioned to obtain an accurate assessment 
of patient risk for PONV/ PDNV. The integration of a Clinical Nurse Specialist (CNS) to the perianesthesia team would assist the nurses in problem identification, critique, and review of the literature, as well as in the design and implementation of practice changes to improve patient outcomes. The CNS is trained to work within and across the patient, nursing, and systems /organizational spheres, and plays a major role in impacting policy. The CNS needs to work to assure that existing guidelines and policies related to prevention of PONV / PDNV are implemented and continuously evaluated. The reduction of PONV/ PDNV rates through the use of standardized risk factor assessment tool can positivity increase patient satisfaction and improve patient outcomes. National adoption will better assure that clinical prevention and population health objectives are met. 


\section{References}

1. McCaffrey R. Make PONV prevention a priority. OR Nurse. 2007; 39-45.

2. Odom-Forren J, Fetzer S J, Moser D K. Evidence-Based Interventions for PostDischarge Nausea and Vomiting: A Review of the Literature. $J$ PeriAnesthesia Nursing. 2006; 21: 411-430.

3. Melton MS, Klein S M, GanTJ. Management of postdischarge nausea and vomiting after ambulatory surgery. Current Opinion in Anesthesiology. 2001; 612-619.

4. Gan T J. Mechanisms Underlying Postoperative Nausea and Vomiting and Neurotransmitter Receptor Antagonist- Based Pharmacotherapy. CNS Drugs. 2007; 813-833.

5. Habib AS, Chen Y T, Hu H, Gan T J, Taguchi A. Postoperative nausea and vomiting following impatient surgeries in a teaching hospital: a retrospective database analysis. Current Medical Research and Opioion. 2006; 22(6): 10931099

6. Chatterjee S, Rudra A, Sengupta S. Current Concepts in the Management of Postoperative Nausea and Vomiting. Anesthesiology Research and Practice. $2011 ; 1-10$.

7. Miaskowski C. A Review of the Incidence, Causes, Consequences, and Management of Gastronintestinal Effects Associated With Postoperative Opioid Administration. J PeriAnesthesia Nursing. 2009; 222-228. 
8. Priesol AJ. Motion sickness. UpToDate. Avaiable at: http://www.uptodate.com/contents/motion-sickness. Accessed June 18, 2012.

9. Kovac AL. Prevention and Treatment of Postoperative Nausea and Vomiting. Drugs. 2000; 59: 213-243.

10. Gan TJ. Risk Factors for Postoperative Nausea and Vomiting. Anesth Analg. 2006; 1884-1898.

11. LeT P, GanT J. Update on the management of Postoperative Nausea and Vomiting and Postdischarge Nausea and Vomiting in Ambulatory Surgery. Anesthesiology Clinics. 2010; 28(2).

12. Apfel CC, Korttila K, Abdalla M, et al. A Factorial trial of Six Interventions for the Prevention of Postoperative Nausea and Vomiting. New Engl J Med. 2004; 350 (24): $2441-2451$.

13. Gan TJ, Meyer TA, Apfel C C, et al. Society for Ambulatory Anesthesia Guidelines for the Management of Postoperative Nausea and Vomiting. Ambulatory Anesthesia. 2007; 1615-1628.

14. ASPAN Evidence-Based Clinical Practice Guideline for the Prevention and/or Management of PONV/PDNV. J PeriAnesthesia Nursing. 2006; 230-250.

15. Odom-Forren J. Measurement of Postdischarge Nausea and Vomiting for Ambulatory Surgery Patients: A Critical Review and Analysis. J PeriAnesthesia Nursing. 2011; 372-383. 
16. WhitePF, O'Hara J F, Roberson C R, et al The Impact of Current Antiemetic Practices on Patient Outcomes: A prospective Study on High-Risk Patients. International Anesthesia Research Society. 2008; 452-458.

17. Wilhelm S, Dehoorne-Smith M, Kale-Prdhan P. Prevention of postoperative nausea and vomiting. ANN Pharmacother. 2007 68-78.

18. Gupta A, Stierer T, Zuckerman R, et al. Comparison of Recovery Profile After Ambulatory Anesthesia with Propofol, Isoflurane, Sevoflurane and Desflurane: A Systematic Review. Anesth Analg. 2004; 98: 632-641.

19. Liu SS, Strodtbeck WM, Richman J M, et al. A Comparison of Regional Versus General Anesthesia for Ambulatory Anesthesia: A Meta-Analysis of Randomized Controlled Trials. Anesth Analg. 2005; 1634-1642.

20. Sinclair DR, Chung F, Mezei G. Can Postoperative Nausea and Vomiting Be Predicted? Anesthesiology. 1999;109-118.

21. Sneyd JR, Carr A, Byrom D, et al. A meta-analysis of nausea and vomiting following maintenance of anaesthesia with propofol or inhalational agents. European Journal of Anesthesiology. 1998; 433-445.

22. Visser K, Hassink EA, Bonsel GJ, et al. Randomized controlled trial of total intravenous anesthesia with propofol versus inhalation anesthesia with isofluranenitrous oxide: postoperative nausea with vomiting and economic analysis. Anesthesiology. 2001;95: 616-626.

23. Myles PS, Leslie K, Chan M, et al. Avoidance of Nitrous Oxide for Patients Undergoing Major Surgery. Ansethesiology. 2007; 221-231. 
24. Apfel CC, Laara E, Koivuranta M, Gremin CA, Roewer N. A Simplified Risk Score for Predicting Postoperative Nausea and Vomiting. Anesthesiology. 1999; 91: 693-700.

25. Cheung B, Heskin R, Hofer K, Gagnon M. The menstrual cycle and susceptibility to coriolis-induced sickness. J Vestibular Research. 2001; 11: 129-136.

26. Golding JF, Kadzere P, Gresty MA. Motion Sickness susceptibility fluctuates through the menstrual cycle. Aviation, Space, and Environmental Medicine. 2005; 76: 970-973.

27. Matchock RL, Levine ME, Gianaros P J, Stern, RM. Susceptibility to Nausea and Motion Sickness as a Function of the Menstrual Cycle. Womens Health Issues. $2008 ; 328-335$.

28. Murphy M, Hooper V, Sullivan E, Clifford T, Apfel C. Identification of risk factors for postoperative nausea and vomiting in the perianesthesia adult patient. $J$ PeriAnesthesia Nurs. 2006; 21 (6): 377-384

29. Palazzo M, Evans R. Logistic Regression Analysis of Fixed Patient Factors for Postoperative Sickness: A Model for Risk Assessment. British J Anesthesia. 1993; 70: 135-140.

30. Koivuranta M, Laara E, Snare L, Alahuhta S. A survey of postoperative nausea and vomiting. Anesthesia. 1997; 443-449.

31. Gundzik K. Nausea and Vomiting in the Ambulatory Surgical Setting. Orthopaedic Nursing. 2008;182-188. 
32. Eberhart LH, Morin AM. Risk scores for predicting postoperative nausea and omiting are clinically useful tools and should be used in every patient: Con-"life is really simple, but we insist on making it complicated". European Society of Anaesthesiology. 2011;155-159.

33. Practice Guidelines for Postanesthetic Care: A Report by the American Society of Anesthesiologists Task Force on Postanesthetic Care. Anesthesiology. $2002 ; 96: 742-52$

34. Apfel CC, Zhang K, George E, et al. Transdermal Scopolamine for the Prevention of Postoperative Nausea and Vomiting: A Systematic Reveiw and Meta-Analysis. Clinical Therapeutics. 2010; 1987-2002.

35. Wender RH. Do current antiemetic practices result in positive patient outcomes? Results of a new study. AMJ Health-Syst Pharm. 2009; S3-S10.

36. Dodd M, Janson S, Facione N, et al. Advancing the science of symptom management. Journal of Advanced Nursing. 2001; 668-676.

37. Kapur P. The big "little Problem". Anesth Analg. 1991; 73: 243-245. 


\section{Appendix A}

\section{Researcher-Developed Data Collection Tool}

\begin{tabular}{|c|c|c|c|c|c|c|c|c|c|c|c|c|}
\hline \multirow[t]{2}{*}{ Age } & \multirow[t]{2}{*}{ Race } & \multirow[t]{2}{*}{$\begin{array}{l}\text { Smoking } \\
\text { History }\end{array}$} & \multirow{2}{*}{$\begin{array}{l}\text { History } \\
\text { of } \\
\text { PONV }\end{array}$} & \multirow{2}{*}{$\begin{array}{l}\text { History } \\
\text { of } \\
\text { Motion } \\
\text { Sickness }\end{array}$} & \multirow[t]{2}{*}{$\begin{array}{c}\text { Anesthesia } \\
\text { Type }\end{array}$} & \multicolumn{3}{|c|}{ Type of Surgical Procedure } & \multirow[t]{2}{*}{$\begin{array}{l}\text { Number of } \\
\text { Antiemetic }\end{array}$} & \multirow[t]{2}{*}{$\begin{array}{c}\text { Use of } \\
\text { Scopolamine }\end{array}$} & \multirow[t]{2}{*}{ PONV } & \multirow[t]{2}{*}{ PDNV } \\
\hline & & & & & & Laparoscopic & Breast & GYN & & & & \\
\hline
\end{tabular}

$\mathrm{PONV}=$ Postoperative Nausea and Vomiting; PDNV= Post Discharge Nausea and

Vomiting; GYN= Gynecological 
